\title{
A study on risk factors of post partum hemorrhage
}

\author{
Rajeshwari, Sreelatha S, Shruthi K, Satish Kumar, Shruthi A, Preethi Malpurae \\ Sandeep Kumar, Satish Dalwai
}

Correspondence: Dr Sreelatha S, Professor; Department of obstetrics \& Gynaecology, ESIC-MC \& PGIMSR, Bangalore. Email - dr.sreelatha2011@gmail.com

Distributed under Attribution-NonCommercial - Share Alike 4.0 International (CC BY-NC-SA 4.0)

\begin{abstract}
Aim: To study the risk factors associated with postpartum haemorrhage. Methodology: Woman with postpartum hemorrhage in the past 3 years from 2015 to 2017 were included in the study. Retrospective data were collected from medical records regarding age, parity, associated risk factors and the mode of management. Results: One hundred forty two (142) women with postpartum hemorrhage were included in the study, and we found that majority of the women were primiparous, in the age group of 25 to 29 years, and, pre-existing anaemia was seen in $11 \%$, PROM in $16 \%$, hypothyroidism in $20 \%$ were found as risk factors and $19 \%$ of the woman underwent secondary LSCS. Conclusion: Postpartum hemorrhage (PPH) is an emergency faced by an obstetrician. It complicates about $3.6 \%$ of all deliveries. It is a potential life- threatening complication of $3 \mathrm{rd}$ stage of labour.
\end{abstract}

Keywords: Postpartum hemorrhage, third stage of labour, caesarean section, hypothyroidism, anaemia.

The commonly accepted definition of postpartum hemorrhage $(\mathrm{PPH})$ is excessive and life-threatening bleeding, which occurs at the time of delivery of the fetus, placenta or following it. Primary PPH is excessive blood loss within 24 hours of delivery. Secondary PPH is any abnormal or excessive bleeding that occurs between 24 hours to 12 weeks after delivery. With a normal vaginal delivery, blood loss is typically $500 \mathrm{ml}$ or less; after a caesarean section, it is usually 800 to $1000 \mathrm{ml}$. Blood loss greater than these amounts to $\mathrm{PPH}$.

Postpartum hemorrhage (PPH) is an obstetric emergency. It is a major cause of maternal mortality and severe morbidity, particularly in low income countries ${ }^{1}$. Timely diagnosis, appropriate resources, and management are critical for preventing death. In a malnourished or anaemic patient the signs of shock can appear with mild bleeding $(<500 \mathrm{ml})^{2}$. Causes of postpartum hemorrhage are commonly referred to as $\left.4 \mathrm{~T}^{\prime}, 1\right)$ Tone: uterine atony is the inability of the uterus to contract and may lead to continuous bleeding. Uterine atony is the most common cause of postpartum hemorrhage. 2) Trauma: Injury to the birth canal which includes the uterus, cervix, vagina and the perineum. The bleeding is substantial as all these organs become more vascular during pregnancy. 3) Tissue: retention of tissue from the placenta or fetus may lead to bleeding. 4) Thrombin: a bleeding disorder occurs when there is a failure of clotting, such as with diseases known as coagulopathies." ${ }^{3}$

Received: $2^{\text {nd }}$ October 2018. Accepted: $17^{\text {th }}$ February 2019.

Rajeshwari, Sreelatha S, Shruthi K, Kumar S, Shruthi A, Malpurae P. A study on risk factors of post partum hemorrhage. The New Indian Journal of OBGYN. 2020; 6(2): 83-6. 
Patients with hypofibrinogenemia (defined as a fibrinogen level $<1.5 \mathrm{~g} / \mathrm{L}$ ) are prone to bleeding when exposed to trauma or after giving birth ${ }^{4}$. Twin pregnancy is a risk factor of PPH. Uterine overdistension is considered to be attributable to PPH via uterine atony in twin pregnancy ${ }^{5}$. Active management of the third stage of labor reduces the incidence and severity of PPH and access to blood transfusion and, if necessary, hysterectomy, which is required in case of severe uncontrolled PPH can prevent mortality and severe morbidity ${ }^{6}$.

\section{Materials and Methods}

This is a retrospective study conducted in the Department of Obstetrics and Gynaecology at ESIC medical college Bangalore. A total of 142 cases of postpartum haemorrhage were included in this study to find out the predisposing factors from 2015 to 2017. Retrospectively data were collected from medical records regarding age, parity, period of gestation, risk factors for PPH, mode of delivery and management. The inclusion criteria were - blood loss over $500 \mathrm{ml}$ at the time of delivery or in the first 24 hours after delivery, and in those cases in which the patients pulse rate, blood pressure, and haemoglobin estimation reflected blood loss of more than $15 \%$. Blood loss was assessed in terms of weight of blood clot collected in a kidney tray. Data regarding women who received blood transfusion post PPH were noted. Blood transfusion for excessive bleeding was defined as a blood transfusion given for a likely $\mathrm{PPH} \geq 1500 \mathrm{ml}$ due to clinical symptoms and signs of anaemia or hemodynamic decompensation after delivery.

Statistical analysis of data was carried out using SPSS statistical software. Quantitative data were analysed with mean, median and standard deviation. Qualitative data (categorical) were analysed with percentages and frequencies. The significance in difference between the two groups were assessed with cross tables, Pearson's chi square test and Fishers exact test were applied where ever necessary.

\section{Results}

Out of 142 cases, $57 \%$ of primigravidas and $42 \%$ of multigravidas had PPH. In our study PPH was seen more commonly in patients of age group 25 to 29 years (table 1). In the present study of postpartum haemorrhage, out of 142 cases $20 \%$ had hypothyroidism and $19 \%$ were Table 1: Parity and age distribution

\begin{tabular}{lll}
\hline Categories & & No. of cases \\
\hline Parity & 0 & 81 \\
& 1 & 53 \\
& 2 & 8 \\
\hline Age in years & $14-19$ & 1 \\
& $20-24$ & 45 \\
& $25-29$ & 63 \\
& $30-34$ & 25 \\
& $35-39$ & 8 \\
\hline
\end{tabular}

secondary LSCS, $17 \%$ had premature rupture of membranes, $8 \%$ had macrosomic babies and $11 \%$ had pre-existing anaemia (table 2).

Table 2: Risk factors associated with PPH

\begin{tabular}{ccc}
\hline Risk factors & $\begin{array}{l}\text { No. } \\
\text { cases }\end{array}$ & $\begin{array}{c}\text { of } \\
\text { Overall \% and in } \\
\text { cases of PPH }\end{array}$ \\
\hline Previous LSCS & 27 & 19 \\
Multiple pregnancy & 4 & 3 \\
Anaemia & 16 & 11 \\
Fibroid uterus & 2 & 1 \\
Placenta previa & 7 & 5 \\
Gestational diabetes mellitus & 18 & 13 \\
Premature rupture of membranes & 24 & 17 \\
Big baby & 9 & 6 \\
Mal presentation & 11 & 8 \\
Hypothyroidism & 29 & 20 \\
Fever & 4 & 3 \\
Instrumental delivery & 4 & 3 \\
Polyhydramnios & 4 & 3 \\
Primary LSCS & 12 & 8.4 \\
\hline Post partm
\end{tabular}

Post partum haemorrhage was controlled with uterotonics in $69 \%$ of cases and $27 \%$ required surgical management like B lynch sutures and subtotal

Table 3: Mode of management

\begin{tabular}{ll}
\hline Categories & No of cases \\
\hline Uterotonics & 99 \\
Surgical management & 39 \\
Hysterectomy & 4 \\
\hline
\end{tabular}

hysterectomy was done in 4 cases due to failed medical line of management for atonic PPH. Blood transfusion was done for 26 cases (table 3).

\section{Discussion}

Pregnancy and childbirth and their consequence remain the leading cause of death, disease and disability among women of reproductive age in developing 
countries like India. In our series of 142 cases we have observed that 81 cases were primigravidas and 61 cases were multigravidas and maximum number of cases were in the age group of 25 to 29 years. We also observed that $20 \%$ had hypothyroidism and $19 \%$ were secondary LSCS, $17 \%$ had premature rupture of membranes, $8 \%$ had macrosomic babies and $11 \%$ had pre-existing anaemia. In 82 cases the mode of delivery was caesarean section and 60 cases were delivered vaginally. Therefore primigravida with age group of 25 to 29 were more prone to postpartum haemorrhage and hypothyroidism, seconadary LSCS, premature rupture of membranes, pre-existing anaemia, were identified as major risk factors.

In Michael S. Kramer et al., study, they found that Labour induction, augmentation of labour, and prior caesarean section are significantly associated with the risk of PPH, and their increase over the study period largely explained the observed rise in PPH in their study. ${ }^{8}$ In Sam Ononge et al., in their study found that caesarean section, multiple pregnancy, fetal macrosomia and HIV are the risk factors for PPH ${ }^{9}$. Jane B Ford et al., in their study on post partum haemorrhage found that $5.8 \%$ of women had PPH in their first pregnancy and $4.5 \%$ had $\mathrm{PPH}$ in their second and $4.5 \%$ of women had PPH in their third pregnancy. ${ }^{10}$ Lao et al., in their study found that parturient aged $\geq 35$ years $(12,686 / 64,886$ or $19.6 \%)$ had significantly increased incidence of PPH. In our study maximum number of cases were in the age group of 25 to 29years. ${ }^{11}$

Hypothyroidism was found as major risk factor for PPH in our study. Post-partum haemorrhages in hypothyroidism are produced both through the uterine hypotony and coagulation problems, with plaque adhesiveness problem. ${ }^{7}$ Rodica Tudosa et al., in their study on maternal and fetal complications of the hypothyroidism related pregnancy, they found that post partum haemorrhage was seen in 18.3 percentage in patients with hypothyroidism. Various studies (Leung, Buckshee, Davis) from the literature indicate a percentage between $7 \%$ and $19 \% .^{7}$ In our study $20 \%$ of the hypothyroid patients had PPH. Therefore hypothyroidism is one of the major risk factor for post partum haemorrhage and post partum haemorrhage should be anticipated at the time of delivery and steps should be taken to control it.
Anaemia in pregnancy is common and linked to postpartum hemorrhage in terms of uterine atony. The more severe the anaemia, the more likely the greater blood loss and adverse outcome. Frass et al., showed that $29.1 \%$ of anaemic women developed PPH during caesarean delivery due to uterine atony. Prior studies have demonstrated that severe anaemia may impair myometrial contractility resulting from impaired transport of hemoglobin and oxygen to uterus causing tissue enzymes and cellular dysfunction. In their study severe uterine atony required emergency hysterectomy which occurred in 39.6\% (32/53) of women who had severe anemia. ${ }^{12}$

Magann et al., in their study found that the PPH rate in nonelective caesarean $(6.75 \%)$ was greater than after elective caesarean $(4.84 \%)$. In our study $19 \%$ of the previous LSCS patients had PPH. ${ }^{13}$ Lill Trine Nyfløt et al., in their study PPH is associated with premature rupture of membranes in $12 \%$ of cases. In our study PPH is associated with PROM in $17 \%$ of cases. ${ }^{14}$

Michael S. Kramer et al., studied a total of 1,03,726 deliveries during their study period, among which 2346 (2.3\%) had a recorded PPH and $157(0.15 \%)$ had a PPH accompanied by a blood transfusion and/or hysterectomy ${ }^{8}$. In our study PPH was controlled with uterotonics in $69 \%$ of cases and $27 \%$ required surgical management like B lynch sutures or Hayman sutures and hysterectomy was done in 4 cases. Blood transfusion was done for 26 cases $(18 \%)$.

\section{Conclusion}

In the present study an attempt has been made to study the high risk factors associated with postpartum haemorrhage. Postpartum haemorrhage is an emergency every obstetrician has to face, often unexpectedly. It complicates about $3-6 \%$ of all deliveries. It is potentially life threatening, and third most common cause of maternal death in developed world. In India it is a leading cause of maternal mortality. Our results suggest that the temporal increase in the incidence of PPH, at least at the study hospital, was attributable to rises in the incidence of several key risk factors, including secondary LSCS, premature rupture of membranes, anaemia, big baby, malpresentation. The clinical situation in which haemorrhage is likely to occur can be better known then anticipatory and preventive treatment can be done before active treatment is necessitated. 
Conflict of interest: None. Disclaimer: Nil.

\section{References}

1. World Health Organization. The world health report: 2005: make every mother and child count. Geneva: WHO; 2005

2. Mousa HA, Blum J, Abou El, Senoun G. Treatment for primary postpartum haemorrhage. Cochrane Database Syst Rev. 2014

3. McLintock C, James AH. Obstetric hemorrhage. J Thromb Haemost. 2011; 9: 1441-51

4. Carroli G, Cuesta C, Abalos E. Epidemiology of postpartum haemorrhage: A systematic review. Best Pract Res Clin Obstet Gynaecol. 2008; 22(6): 9991012.

5. ACOG Practice Bulletin Number 76. Postpartum hemorrhage. ObstetGynecol. 2006;108(4): 1039-47.

6. Cabero Roura L, Keith LG. Post-partum haemorrhage: diagnosis, prevention and management. J Matern Fetal Neonat Med. 2009; 22(Suppl 2): 38-45.

7. Abalovich M, Gutierrez S, Alcaraz G, Maccallini G, Garcia A, Levalle O. Overt and subclinical hypothyroidism complicating pregnancy. Thyroid. 2002;12(1): 63-6.

8. Kramer M, Dahhou M, Vallerand D, Liston R, Joseph K. Risk Factors for Postpartum Hemorrhage: Can We Explain the Recent Temporal Increase? Journal of Obstetrics and Gynaecology Canada. 2011; 33(8): 810-19.

9. Ononge S, Mirembe F, Wandabwa J, Campbell O. Incidence and risk factors for postpartum hemorrhage in Uganda. Reproductive Health. 2016;13(1): 38 .
10. Ford J. Postpartum haemorrhage occurrence and recurrence. The Medical Journal of Australia. 2007; 187(7): 391-3.

11. Lao, Terence, Sahota, Daljit, Cheng, Yvonne, et al. Advanced Maternal Age and Postpartum Hemorrhage - Risk Factor or Red Herring?. The journal of maternal-fetal \& neonatal medicine : the official journal of the European Association of Perinatal Medicine, the Federation of Asia and Oceania Perinatal Societies, the International Society of Perinatal Obstetricians. 2013; 27: 10.3109/ 14767058. 2013. 807240.

12. Kaima FA. Postpartum hemorrhage is related to the hemoglobin levels at labor: Observational study. Alexandria Journal of Medicine. 2015; 51(4): 33337.

13. Magann, Everett, Evans, Sharon, Hutchinson, Maureen, et al. Postpartum Hemorrhage After Cesarean Delivery: An Analysis of Risk Factors. Southern medical journal. 2005; 98. 681-5.

14. Nyflot LT, Sandven I, Stray-Pedersen B, Pettersen S, Al-Zirqi I, Rosenberg M, et al. Risk factors for severe postpartum hemorrhage: a case-control study. BMC Pregnancy and Childbirth. 2017; 17(1): 17. doi: $10.1186 /$ s12884-016-1217-

\footnotetext{
Rajeshwari ${ }^{1}$, Sreelatha $S^{2}$, Shruthi $K^{3}$, Satish Kumar ${ }^{4}$, Shruthi $A^{5}$, Preethi Malpurae ${ }^{6}$, Sandeep Kumar ${ }^{7}$, Satish Dalwai $^{8}$

$1,3,4,5,6,7,8$ Junior resident; ${ }^{2}$ Professor; Department of Obstetrics \& Gynaecology, ESIC-MC \& PGIMSR, Bangalore
} 